\title{
The use of green tea (Camellia sinensis) as a phytogenic substance in poultry diets
}

\author{
Authors: \\ Sohail H. Khan ${ }^{1}$ \\ Affiliations: \\ ${ }^{1}$ Poultry Research Institute, \\ Pakistan \\ Correspondence to: \\ Sohail Khan \\ Email: \\ sohailhassan64@gmail.com \\ Postal address: \\ Poultry Research Institute, \\ Murree Road, Shamsabad, \\ Rawalpindi 46000, Pakistan

\section{Dates:} \\ Received: 04 Nov. 2013 \\ Accepted: 12 Feb. 2014 \\ Published: 15 Apr. 2014 \\ How to cite this article: \\ Khan, S.H., 2014, 'The use of \\ green tea (Camellia sinensis) \\ as a phytogenic substance in \\ poultry diets', Onderstepoort \\ Journal of Veterinary \\ Research 81(1), Art. \#706, \\ 8 pages. http://dx.doi. \\ org/10.4102/ojvr.v81i2.706

\section{Copyright:} \\ (C) 2014. The Authors. \\ Licensee: AOSIS \\ OpenJournals. This work \\ is licensed under the \\ Creative Commons \\ Attribution License.
}

This review examined the use of green tea (Camellia sinensis) in the diets of poultry. Research findings were obtained from various recent studies, where much attention was focused on the role of green tea in the promotion of both animal and human health. The review involved some of the currently available information about green tea, pertaining to its chemical composition, anticoccidial and antimicrobial effect, effect on broiler and layer performance and on blood and egg yolk constituents. To the author's knowledge this is the first review paper on this topic. It will be helpful for poultry nutritionists and the poultry industry, although more detailed studies are still needed to elucidate the effects of green tea in poultry nutrition under various circumstances.

\section{Introduction}

As a result of the ban on the use of antibiotic growth promoters in animal diets in the European Union as from January 2006, and the growing pressure on livestock producers in other parts of the world, alternative substances and strategies for animal growth promotion are being investigated. In this context, phytogenic and herbal products have received increased attention, because as natural additives they have a high acceptability amongst consumers (Toghyani et al. 2010). Phytogenic feed additives (also called phytobiotics or botanicals) are commonly defined as plantderived compounds. They are incorporated into diets to improve the productivity of livestock through amelioration of feed properties, promotion of the animals' production performance, and the quality of food derived from those animals (Windisch et al. 2007). Phytogenic feed additives comprise a wide variety of herbs (flowering, non-woody and non-persistent plants), spices (herbs with an intense smell or taste commonly added to human food) and essential oils (volatile lipophilic compounds derived by cold expression or by steam or alcohol distillation), or oleoresins (extracts derived by nonaqueous solvents). This class of feed additives has recently enjoyed increasing interest, especially for use in swine and poultry, as can be seen from a significant increase in the number of scientific publications from 2000 onwards. Green tea (Camellia sinensis) is also included in the list of phytogenic substances.

Next to water, tea is one of the world's most highly consumed beverages and it has attracted much attention in recent years due to its numerous health benefits (Perumalla \& Hettiarachchy 2011). Tea was accidentally discovered by Shen Nung, a Chinese emperor, in 2737 BC. When some leaves fell into boiling water, producing a distinct taste and fragrance, it was pronounced to be heaven- sent by the emperor (Wheeler \& Wheeler 2004). Tea (Camellia sinensis L.) is a perennial, evergreen and cross-pollinated plant bearing white flowers and green fruits with two to three seeds. The difference in the flavour, colour and name of the tea depends on how the leaves are processed. There are four basic types of tea: black tea (tea leaves that are exposed to the air and allowed to fully oxidise or ferment, changing the leaves from green to black); oolong tea (it falls between black and green tea); green tea (less processed and not fermented); and white tea (the least processed of all teas).

The polyphenolic compounds of green tea have been shown to improve body weight gain and feed efficiency in pigs (Hossain, Seok \& Chul 2012), cattle (Sarker et al. 2010b) and broilers (Biswas \& Wakita 2001a). Ensiled or oven-dried green tea by-products have also been evaluated in goats for their nutritive potential as protein feedstuffs (Kondo, Kazumi \& Hiro-Omi 2007). These compounds also maintain microflora balance and exhibit antimicrobial effects against pathogenic bacteria (Guray et al. 2011; Hara-Kudo et al. 2005). It has been reported that green tea polyphenols have strong anti-oxidative properties (Nishida et al. 2006); this is demonstrated by a reduction in thiobarbituric acid reactive substances (TBARS) values and by maintaining the oxidative stability of broiler meat (Yang et al. 2003) and egg yolk (Uuganbayar et al. 2005). The green tea leaves, their by-products, and tea polyphenols can be offered as an ingredient or as a supplement to broiler feed for reducing mortality in diseased birds (Cao, Karasawa \& Guo 2005) and to hens for improving laying performance (Uuganbayar et al. 2005, 2006), and for reducing the cholesterol content of 
eggs. Yang et al. (2003) also reported that cholesterol levels were decreased and fatty acids of plasma and meat were improved when the animals were fed different levels of green tea by-products. In poultry diets, green tea and its derivatives like green tea extract, green tea leaves, green tea by-products, green tea polyphenols and green tea flowers are supplemented for improving performance.

The aim of this article was to review the most recent studies on the beneficial effects of green tea and to evaluate its potential interest as a component of poultry diets.

\section{Chemical components}

The chemical composition and other properties of green tea are complex. Abdo et al. (2010) found that air-dried green tea leaves contained $7.80 \%$ moisture, $92.20 \%$ dry matter, $82.40 \%$ organic matter, $18.15 \%$ crude protein, $8.72 \%$ ether extract, $19.32 \%$ crude fibre, $9.80 \%$ ash, $36.21 \%$ nitrogen free extract and $3002 \mathrm{kcal} / \mathrm{kg}$ calculated metabolisable energy (ME).

Green tea has over 200 bioactive compounds and contains over 300 different substances (Labdar 2010). The chemical composition of tea is multifaceted, consisting of polyphenols (catechins and flavanoids), alkaloids (caffeine, threobromine, theophylline), volatile oils, polysaccharides, amino acids, lipids, vitamin C, minerals and other uncharacterised compounds (Karori et al. 2007).

\section{Amino acids}

Green tea contains many amino acids, but L-theanine, specific to the tea plant, is the most abundant, accounting for $50.00 \%$ of the total amino acids. This form of theanine acts as an antioxidant, protecting cells from free radical damage, and also helping to induce relaxation and prevent anxiety by increasing serotonin and dopamine levels in nerve cells. Amino acid degradation is involved in the biogenesis of the tea aroma (Balentine 1997). Abdo et al. (2010) reported that green tea leaves contained amino acids as $1.35 \%$ aspartic, $0.64 \%$ therionine, $0.67 \%$ serine, $1.98 \%$ glutamic, $0.68 \%$ proline, $0.76 \%$ glycine, $0.78 \%$ alanine, $0.78 \%$ valine, $0.55 \%$ isoleucine, $1.17 \%$ leucine, $0.57 \%$ tyrosine, $0.78 \%$ phenylalanine, $0.32 \%$ histidine, $0.85 \%$ lysine, $0.74 \%$ argnine, $0.37 \%$ methionine and $0.14 \%$ cystine. More than 600 different molecules of volatile fractions of tea have been isolated. These include terpenoids and degradation products of amino acids, carotenoids and linoleic acid (Hara et al. 1995).

\section{Carbohydrates}

Amongst the bio-active compounds found in green tea, the largest component present in green tea leaves is carbohydrates (cellulosic fibre). The simplest compounds are catechins, a group of flavanoids called flavan-3-ols (Yilmaz 2006). These catechins are synthesised in tea leaves through malonic acid and shikimic acid metabolic pathways with gallic acid as an intermediate derivative (Naidu 2000). Catechins are colourless, water-soluble compounds that impart bitterness and astringency to green tea infusions (Wang et al. 2000). Catechins constitute $15.00 \%$ to $30.00 \%$ of dry weight of green tea leaves, as opposed to $8.00 \%$ to $20.00 \%$ of oolong and $3.00 \%$ to $10.00 \%$ of black tea (Amidor 2009). Green tea extract contains six primary catechins, namely epicatechin (EC), epicatechin gallate (ECG), epigallocatechin (EGC) and epigallocatechin-3-gallate (EGCG) (Kajiya et al. 2004). Epigallocatechin-3-gallate is the most important and wellstudied tea catechin owing to its high content $(50.00 \%)$ in tea. It also has the most potent physiological properties in comparison to other components (Taylor et al. 2005). Ester-type catechins ECG and EGCG are more bitter and astringent than EC and EGC and these flavanoids have a greater synergistic action than individual tea components (Fujiki 1999). Uuganbayar et al. (2006) reported that total catechin contents were $15.73 \%$ for Korean green tea, $15.60 \%$ for Japanese green tea and $14.04 \%$ for Chinese green tea. Of the total catechin components, EGC was predominant, accounting for $67.50 \%$ (Korean green tea), 67.90\% (Japanese green tea) and 63.80\% (Chinese green tea) of the total catechin contents. In another study, green tea leaves contained active constituents of $1.01 \%$ total phenols, $105 \mathrm{mg} / \mathrm{kg}$ caffeine, $50 \mathrm{mg} / \mathrm{kg}$ catechin, $35 \mathrm{mg} / \mathrm{kg} \mathrm{EC}, 185 \mathrm{mg} / \mathrm{kg}$ ECG and $17.5 \mathrm{mg} / \mathrm{kg}$ ascorbic acid (Abdo et al. 2010). The catechin content showed considerable variability in one study. The levels of EGCG ranged from $117 \mathrm{mg} / \mathrm{L}$ - $442 \mathrm{mg} / \mathrm{L}$, EGC from $203 \mathrm{mg} / \mathrm{L}$ - $471 \mathrm{mg} / \mathrm{L}$, ECG from $16.9 \mathrm{mg} / \mathrm{L}-150.0 \mathrm{mg} / \mathrm{L}, \mathrm{EC}$ from $25 \mathrm{mg} / \mathrm{L}-81 \mathrm{mg} / \mathrm{L}$ and catechin from $9.03 \mathrm{mg} / \mathrm{L}-115.00 \mathrm{mg} / \mathrm{L}$. Moreover, caffeine contents in the green tea infusions studied were between $141 \mathrm{mg} / \mathrm{L}$ and $338 \mathrm{mg} / \mathrm{L}$ (Reto et al. 2007).

\section{Minerals}

Minerals comprise about $4.00 \%-9.00 \%$ of the inorganic matter of tea (Chaturvedula \& Prakash 2011). Abdo et al. (2010) assayed the mineral content profile in green tea leaves as $4.66 \%$ calcium, $1.62 \%$ total phosphorus, $865.1 \mathrm{mg} / \mathrm{kg}$ manganese, $146.3 \mathrm{mg} / \mathrm{kg}$ zinc and $858.1 \mathrm{mg} / \mathrm{kg}$ selenium. Similarly, Reto et al. (2007) evaluated some minerals in green tea samples and reported that potassium was found in larger amounts $(92 \mathrm{mg} / \mathrm{L}-151 \mathrm{mg} / \mathrm{L})$, whereas the content of sodium, calcium, fluoride, aluminium, manganese and iron were $35 \mathrm{mg} / \mathrm{L}-69 \mathrm{mg} / \mathrm{L}, 1.9 \mathrm{mg} / \mathrm{L}-3.5 \mathrm{mg} / \mathrm{L}, 0.8 \mathrm{mg} / \mathrm{L}$ - $2.0 \mathrm{mg} / \mathrm{L}, 1.0 \mathrm{mg} / \mathrm{L}-2.2 \mathrm{mg} / \mathrm{L}, 0.52 \mathrm{mg} / \mathrm{L}-1.90 \mathrm{mg} / \mathrm{L}$, $0.020 \mathrm{mg} / \mathrm{L}-0.128 \mathrm{mg} / \mathrm{L}$, respectively. Costa, Gouveia and Nobrega (2002) observed large variations in the mineral content (aluminium, calcium, magnesium and manganese) in green tea from different origins. Shu et al. (2003) observed marked variations amongst different tea varieties in accumulating fluoride and aluminium. Xu et al. (2003) reported that the content of selenium in green teas was greatly increased by foliar application of selenium-enriched fertilisers; moreover, the selenium-enriched green tea exhibited significantly higher antioxidant activity than regular green tea.

\section{Anticoccidial and antimicrobial effects of green tea Anticoccidial effects}

Positive effects of green tea have been demonstrated in poultry diseases including coccidiosis (Jang et al. 2007) and avian influenza (Deryabin et al. 2008; Song et al. 2007). Seven 
species of Eimeria (an intracellular protozoan) belonging to the phylum Apicomplexa cause avian coccidiosis, which is an economically important disease in the poultry industry. Eimeria infection causes extensive destruction of the intestinal epithelium that results in reduced feed efficiency, body weight gain and a temporary reduction in egg production (Dalloul \& Lillehoj 2005).

To date, only one study demonstrating an anticoccidial effect of green tea on Eimeria parasites has been published (Jang et al. 2007). The results showed that green tea (0.5\% and $2.0 \%)$ fed to five-week-old chickens for two weeks prior to infection with Eimeria maxima (E. maxima) (10 000 sporulated oocysts per bird) significantly $(p<0.05)$ reduced shedding of oocysts in faeces by $38.5 \%$ and $51.5 \%$, respectively. The green teabased diet, however, did not improve body weight loss due to infection with E. maxima. In general, the higher concentration of green tea supplementation showed a greater protective effect and reduction in faecal oocyst shedding. In this regard, green tea components have shown anti-parasitic activities in vitro by inhibiting egg hatching and larval development and inactivating the infective larvae of Teladorsagia circumcincta and Trichostrongylus colubriformis (Molan et al. 2003, 2004). In view of the fact that hosts are infected by contaminated litter in the chicken houses, significant reduction of faecal oocyst shedding by green tea in the diet would lead to less environmental contamination by coccidia parasites. The fundamental mechanism responsible for green tea-mediated protection against coccidiosis is as yet unknown. However, many cytokines are known to elicit a protective cellmediated immune response against intracellular pathogens including coccidia. An increased level of IFN- $\gamma$, in particular, has been associated with protective immunity against avian coccidiosis (Yun et al. 2000). This subject needs to be further investigated in the other species of coccidia that infect chickens.

\section{Antiviral effects}

Numerous outbreaks of avian influenza virus infection (A/H5N1) have occurred recently, infecting domestic birds, chicken and ducks. The possibility of the emergence of a new strain of influenza virus capable of causing a pandemic in humans is potentially high and no vaccine effective against such a strain currently exists. Song et al. (2007) synthesised catechin derivatives with different alkyl chain lengths and aromatic ring substitutions at the 3-hydroxyl group from EGC and catechin and their anti-influenza-viral activity was evaluated in vitro and in ovo. Marked antiviral activity was observed for derivatives carrying moderate chain lengths (7-9 carbons) compared to those with aromatic rings, whereas the 5'-hydroxyl group of the trihydroxy-benzyl moiety did not significantly contribute to antiviral activity. The derivatives exerted inhibitory effects for all six influenza subtypes tested, including three major types of currently circulating human influenza viruses (A/H1N1, A/H3N2 and B type), H2N2 and H9N2 avian influenza virus. The compounds strongly inhibited adsorption of the viruses on red blood cells. They also restricted the growth of avian influenza virus in ovo, with a minimum inhibition concentration of $5 \mu \mathrm{M}$ to $10 \mu \mathrm{M}$; this far exceeds that of the neuraminidase inhibitor oseltamivir or M2 proton channel inhibitor amantadine. The antiviral activity appears to be mediated by interaction with haemagglutinin (HA) or viral membrane, rendering HA less fusogenic at the initial stage of infection. The broad spectrum activity against various subtypes of influenza viruses may complement the limitations of current antivirals and contribute to managing potentially emerging influenza pandemics. The structureactivity data of catechin derivatives may usefully guide future research endeavours for applying green tea catechins as alternative anti-viral agents. Subsequently Deryabin et al. (2008) investigated the potential anti-viral activity of a unique nutrient mixture (NM) (containing green tea extract, lysine, proline, ascorbic acid, N-acetyl cysteine and selenium, amongst other micronutrients) and its components on A/H5N1 at viral dosages of 1.0, 0.1 and $0.01 \mathrm{TCID}_{50}$. Antiviral activity was studied in cultured cell lines PK, BHK-21, and Vero-E6. Virus lysing activity was determined by coincubation of virus $\mathrm{A} / \mathrm{H}_{5} \mathrm{~N}_{1}$ with $\mathrm{NM}$ for 0 minutes to 60 minutes, followed by residual virulence titration in cultured SPEV or BHK-21 cells. The NM demonstrated high antiviral activity evident even at prolonged periods after infection. Its antiviral properties were comparable to those of conventional drugs (amantadine and oseltamivir); however, NM had the advantage of affecting viral replication at the late stages of the infection process.

\section{Effects on intestinal flora}

The caecum is one of the areas of greatest microbial activity in the gastrointestinal tract of chickens. Intestinal microflora plays an important role in the health status of host animals. Therefore, a common approach to maintain host gut health is to increase the number of desirable bacteria in order to inhibit colonisation by invading pathogens (Guo et al. 2004). Terada et al. (1993) studied the effects of green tea polyphenols (GTP) on the caecal flora in eight 24-day-old and eight 56-day-old chickens that had consumed a basal diet or a diet supplemented with tea polyphenols ( $2 \mathrm{~g} / \mathrm{kg}$ diet $)$ for periods of up to 56 days. On day 24 of the experiment, the number of total bacteria and bacteroidaceae significantly decreased, but staphylococci increased. The frequency of the occurrences of pseudomonads and yeasts significantly increased, but that of moulds decreased. This may be associated with the fact that the caecal flora of the chicken is not established until four weeks of age, as reported by Barnes et al. (1972). On day 56, lactobacilli increased to some extent, but enterobacteriaceae, including the detection rate of Proteus, showed a significant decrease. It seems that the activities of the intestinal flora may lead to lower $\mathrm{pH}$ and a decrease in caecal putrefactive bacteria such as Proteus. Cao et al. (2005) observed the effects of GTP supplement on counts of caecal microflora in female broiler chickens fed on semi-purified diets from 28 days to 42 days of age. They found that the counts of bifidobacteria, bacteroidaceae, Peptococcaceae, lactobacilli, Eubacteria and lecithinase-positive bacteria (clostridia, streptococci, staphylococci and bacilli) in the GTP group were lower than those of the control group. They reported that green tea and its chemical 
components show antibiotic-like effects of non-selectively decreasing total counts of all microflora. Murali et al. (2012) evaluated the effect of marinating chicken breast fillets with extracts of lemon, green tea and turmeric against Campylobacter jejuni (C. jejuni) and Salmonella enteritidis. This combination was found to be most effective against C. jejuni and Salmonella enteritidis. All the bacteria were killed within 12 hours of incubation, there was a five-log reduction in growth within one hour of incubation, and it proved to be more effective than any of the extracts used alone. Furthermore, combination of both lemon and green tea killed all C. jejuni isolates, but not Salmonella enteritidis, within 24 hours of incubation.

Polyphenols extracted from green tea have been shown to have inhibitory effects on Gram-positive bacteria as well as Gram-negative bacteria (Gadang et al. 2008). The efficacy of green tea extract against various bacterial strains can be related to differences in cell membranes (Ikigai et al. 1993). Yoda et al. (2004) investigated the antibacterial activities of EGCG on various strains of Staphylococcus (Gram positive cocci) and Gram negative rods including Escherichia coli, Klebsiella pneumoniae and Salmonella. They found that $50 \mu \mathrm{g} / \mathrm{mL}-100 \mu \mathrm{g} / \mathrm{mL}$ was required to inhibit growth of Staphylococcus and concentrations higher than $800 \mu \mathrm{g} / \mathrm{mL}$ were required to inhibit Gram-negative rods. Hara-Kudo et al. (2005) studied the antibacterial effects of catechins (major GTP) using Clostridium and Bacillus spores. Incubation with crude catechins decreased the number of Clostridium botulinum (C. botulinum) and Clostridium butyricum (C. butyricum) spores, but not Bacillus cereus (B. cereus) spores. Furthermore, the effects of six catechin derivatives on spores were investigated. The epicatechin gallate, EGC, EGC and gallocatechin gallate (GC) were more effective in decreasing C. botulinum and C. butyricum spore numbers than catechin and EC. The vegetative growth of C. botulinum and B. cereus was inhibited by crude extracts of the catechins. Specifically, purified GC and EGC inhibited the vegetative growth of C. botulinum and B. cereus. The inhibitory effect of EC on B. cereus was similar to that of GC. However, toxin-production by $B$. cereus was not inhibited by catechin. Damage to the membrane of $C$. butyricum spores by catechin derivatives was shown using fluorescent microscopy. This study showed that low concentrations of catechins, although requiring a long exposure time, inhibited the growth of bacterial spores. However, the effects of the purified derivatives of the catechins were not the same and GC and EGC were found to be the most potent. Spores that are generally resistant to many disinfectants were sensitive to catechins. In another study, amongst the catechins present in green tea extract, EGCG and ECG were the most potent in exhibiting antimicrobial activity due to the galloyl moiety present in their structures (Shimamura, Zhao \& Hu 2007).

\section{Effect of green tea on broilers' performance}

In this review, it was found that green tea inclusion in broiler diets had positive effects on growth performance and lean meat production of the broilers. Biswas and Wakita (2001a) added four levels of green tea powder $(0.50 \%, 0.75 \%, 1.00 \%$ and $1.50 \%$ ) to broiler starter and finisher diets. Supplemental green tea powder tended to decrease feed intake and body weight gain at a higher dose, but tended to improve FCR. Dressing percentage was not affected by green tea, although proportions of some parts of the carcass were influenced. The proportion of thigh meat was increased by the $1.50 \%$ level feed while that of wing meat was decreased in all treatment groups. The quantity and percentage of abdominal fat were decreased significantly with supplementation. Similar findings, namely that when the green tea by-product level was increased the percentage of abdominal fat decreased in broilers, were reported by Yang et al. (2003) and Guray et al. (2011). Kaneko et al. (2001) reported that 1.00\%, 2.50\% and $5.00 \%$ of green tea in broiler diets linearly reduced body weight gain of the chicks. Similarly, Uuganbayar (2004) also reported that $1.00 \%$ to $1.50 \%$ green tea supplement in broiler diet had the effect of reducing body weight gain of the chicks. Yang et al. (2003) determined the optimum level of green tea by-product $(0.50 \%, 1.00 \%$ and $2.00 \%)$ in diets without antibiotics and evaluated its effect on broiler performances. They observed non-significant differences in feed intake and feed efficiency amongst treatments.

Similar results were reported by Cao et al. (2005) indicating that body weight gain, feed intake and feed efficiency from 28 days to 42 days of age were not improved; however, mortality was significantly reduced by supplementation with green tea by-products. Recently, Shomali, Najmeh and Saeed (2012) investigated the effects of high levels of green tea powder $(1.0 \%, 2.0 \%$, or $4.0 \%)$ on broiler growth performance for two weeks. Differences in body weight, feed intake and FCR were insignificant as well. In contrast to the above studies, Sarker, Kim and Yang (2010a) observed significantly increased weight gain $(1210.61 \mathrm{~g} /$ bird) in broilers during the finishing period at the $0.5 \%$ level compared to the $1.0 \%$ (1033.36 g/bird) level of green tea. Guray et al. (2011) supplemented a liquid hydroalcoholic extract of fresh green tea $(0.1 \mathrm{~g} / \mathrm{kg}$ or $0.2 \mathrm{~g} / \mathrm{kg})$ in broiler diets. The dietary green tea extract increased the body weight, feed efficiency, carcass weight and dressing percentage. The broilers in green tea supplemented groups consumed more feed than the control birds throughout the entire experimental period. The relative gut length of broilers in the high level of green tea group tended to be lower than those in the control group. The dietary green tea extract increased redness (1) and yellowness (2) values of the breast meat. Thus, the green tea extract appeared to have a measurable impact on CIE colour values of the breast meat in broilers. The authors concluded that the improved production results in the broilers with added green tea extract are directly connected with physiological mechanisms such as the regulation of the caecal microflora.

The production sources of green tea used in all of the above studies were different, for example: Japanese green tea powder (Biswas \& Wakita 2001a; Kaneko et al. 2001); Japanese and Chinese green tea or their polyphenols (Cao 
et al. 2005); Korean green tea powder (Sarker et al. 2010a; Yang et al. 2003); and eastern Black Sea coast of Turkey tea powder (Guray et al. 2011). All of these green tea sources had different compositions. The inconsistency amongst the studies may be explained by the differences in total catechin content and its major components such as epicatechin, epigallocatechin, epicatechin gallette, epigallocatechin gallette, of the green tea and green tea extract used in these studies.

\section{Effect of green tea on layers' performance}

Yamane et al. (1999) reported that 0.67\% Japanese green tea extracts mixed with drinking water slightly reduced the egg weight of the hens. Similarly, Biswas and Wakita (2001b) also reported that $0.30 \%$ green tea powder lowered average egg weight. In contrast to these results, Uuganbayar et al. (2005) observed that up to $2.00 \%$ green tea powder in layer diets had no adverse effect on egg production rate and egg weight compared with the control. Sadao and Yuko (2008) found that there was no significant difference in egg weight, rate of egg production or egg mass between the control group and the group of laying hens fed on diets supplemented with $1.00 \%$ green tea, while $5.00 \%$ and $10.00 \%$ resulted in the lowest values. Similar results were obtained by Biswas et al. (2000), who reported that the addition of $0.60 \%$ Japanese green tea to the layer diet had no effect on egg production rate of hens in a long-term feeding experiment. Recently, Ariana et al. (2011) observed that supplementation of layer diets with $0.50 \%$ extract of green tea and $1.50 \%$ powder of green tea had no significant effects on feed intake, egg production and egg weight.

In contrast to above studies, Yang et al. (2003) reported that hens fed diets containing $4.00 \%$ and $6.00 \%$ green tea byproduct showed a significantly increased egg production rate. Al-Harthi (2004) reported that the addition of $0.20 \%$ green tea yielded significantly better egg production and egg mass than the control group. Abdel-Azeem (2005) reported that the addition of powdered green tea flowers at $0.25 \%, 0.50 \%$ and $0.75 \%$ to a Japanese quail grower diet improved feed conversion, especially at the $0.75 \%$ level. He attributed the effect on feed conversion to the biological role of flavonoids present in green tea in terms of antimicrobial, antifungal, antiseptic and anti-inflammatory activities or the role of green tea as an antioxidant. Uuganbayar et al. (2006) compared the effects of two levels $(1.00 \%$ or $2.00 \%)$ each of Korean, Japanese and Chinese green tea on laying performance. The results showed that egg production rates of the layers that were fed diets containing $1.00 \%$ or $2.00 \%$ green tea powders were significantly increased compared to that of the control. The feed intake was significantly decreased in Korean green tea and Chinese green tea groups at $2.00 \%$ inclusion levels. They concluded that incorporation of $1.00 \%$ or $2.00 \%$ Korean, Japanese and Chinese green tea into layer diets regardless of origin had favourable effects on laying performance. Sahin et al. (2010) found that $200 \mathrm{mg}$ or $400 \mathrm{mg}$ of EGCG exerted antioxidant effects and linearly improved feed intake from $29.6 \mathrm{~g} /$ day to $30.9 \mathrm{~g} /$ day and egg production from $84.30 \%$ / day to $90.10 \%$ / day in heat-stressed quails. Abdo et al. (2010) investigated the effect of adding green tea leaves $(1.00 \%$ to $5.00 \%)$ and its aqueous extract $(0.5 \mathrm{~L} / 100 \mathrm{~kg}$ to $2.5 \mathrm{~L} / 100 \mathrm{~kg}$ of ration) to laying-hen diets. The results revealed that the improvements in egg production, egg mass and feed conversion values due to $1.00 \%$ green tea leaves compared to the control were $5.59 \%, 6.79 \%$ and $7.84 \%$, respectively. The corresponding level $(0.5 \mathrm{~L} / 100 \mathrm{~kg}$ diet $)$ of hot water green tea extract resulted in improvements of $6.78 \%, 7.46 \%$ and $8.65 \%$, respectively.

Egg quality also improved with supplementation of green tea in layer diets. Biswas and Wakita (2001a) found that a low level of green tea powder $(0.3 \%)$ improved the Haugh unit, and albumen percentage was higher, but yolk percentage was lower in the green tea powder group. Uuganbayar et al. (2005) found that eggshell thickness was reduced significantly in the layer group fed the diets containing green tea powder regardless of dietary levels $(0.5 \%, 1.0 \%, 1.5 \%$ and $2.0 \%)$. The yolk colour score (yellowness of egg yolk) was increased in the layers fed the $2.0 \%$ green tea diet compared with that of the control diet. Later, Uuganbayar et al. (2006) reported that the eggshell thickness and shape index were significantly reduced in layers fed $1.0 \%$ or $2.0 \%$ Japanese green tea diets compared to that of the control. However, there were no significant differences in eggshell thickness of layers fed diets containing Korean and Chinese green tea inclusions compared to that of the control. Sensory evaluation in terms of juiciness, texture, flavour and acceptability of boiled eggs did not vary between the green tea-supplemented treatments and control treatments. The albumen index, yolk index and Haugh unit of the eggs were no different between green tea and control treatments. However, Yamane et al. (1999) and Biswas et al. (2000) reported that Japanese green tea inclusion in the layer diet improved the Haugh unit score of the eggs. They indicated that the improvement of the Haugh unit score with green tea feeding was accompanied by a greater albumen height and physical stability of egg albumen. Bravo (1998) showed that albumen tended to be thicker in groups fed green tea powder and attributed this effect to the possible transfer of green tea powder polyphenols into $\beta$-ovomucin. The $\beta$-ovomucin increases albumen durability by forming complexes with proteins and polysaccharides.

On other hand, Sadao and Yuko (2008) reported that there were no significant differences in the yolk colour fan score or strength of the eggshell for four treatments (green tea powder added $0.00 \%, 1.00 \%, 5.00 \%$ and $10.00 \%$ of the hen diets). However, they observed that eggshell strength, thickness of the eggshell and Haugh unit values decreased with increasing green tea powder intake, especially in the $10.00 \%$ group. Abdo et al. (2010) reported that more than $1.00 \%$ green tea leaves $(3.00 \%$ and $5.00 \%)$ and more than 0.5 $\mathrm{L} / 100 \mathrm{~kg}$ diet green tea extract $(1.5 \mathrm{~L} / 100 \mathrm{~kg}$ and $2.5 \mathrm{~L} / 100$ $\mathrm{kg}$ ) were required to improve both external and internal egg quality parameters significantly. The improvement in shell thickness values due to $3.00 \%$ green tea leaves or the 
corresponding level (1.5 L/100 kg diet) of aqueous extract compared to the control was $6.88 \%$. Yolk colour score was not influenced significantly by any of the treatments. However, there was a steady increase in yolk colour score with increasing levels of green tea leaves. Regarding yolk colour, the results revealed that there was a $13.29 \%$ increase of $\beta$-carotene in animals fed green tea leaves and according to Naber (1979), $\beta$-carotene is an important precursor for vitamin A, which upon colourisation is categorised as yellow. However, the amount found in egg yolks is only one tenth of the amount of xanthophylls, so its influence on colour is reported to be insignificant. Recently, Ariana et al. (2011) found that egg quality such as yolk colour, albumen height, Haugh units, eggshell breaking strength and shell thickness were unaffected by $0.50 \%$ extract of green tea and $1.50 \%$ powder of green tea. However, yolk weight and yolk index were significantly improved by the green tea treatments.

\section{Effect of green tea on blood and egg yolk constituents}

El-Deek and Al-Harthi (2004) showed that the addition of green tea at $5 \mathrm{~g} / \mathrm{kg}$ of broiler feed had no significant effect on the chemical composition of plasma total lipids, cholesterol, plasma aspartate aminotransferase and alanine aminotransferase activities. Abdel-Azeem (2005) found that the addition of powdered green tea flowers at $0.25 \%, 0.50 \%$ and $0.75 \%$ to growing Japanese quail diets improved antibody titre production. They also found that raising the level of green tea from $0.25 \%$ to $0.75 \%$ significantly decreased blood lipid fractions and increased high-density lipoprotein (HDL). Yang et al. (2003) reported that the addition of green tea by-product to diets tended to decrease blood low-density lipoprotein (LDL) cholesterol content compared to the control group, although there were no significant differences amongst treatments. The addition of green tea by-product increased docosahexaenoic acid (DHA) in blood plasma and tended to decrease the cholesterol content in chicken meat, but a significant difference was not observed. An optimum level of DHA, belonging to the omega3 fatty acids group, may play an important role in the control of blood pressure and blood cholesterol content. Abdo et al. (2010) reported that the addition of $3.00 \%$ and $5.00 \%$ green tea leaves, or between $0.5 \mathrm{~L} / 100 \mathrm{~kg}$ and $2.5 \mathrm{~L} / 100 \mathrm{~kg}$ green tea extract to hens' diets significantly dicreased both total blood plasma cholesterol and total lipids. They also found that $1.5 \mathrm{~L} / 100 \mathrm{~kg}$ green tea extract was required to increase the beneficial blood plasma HDL compared with the control. The reduction in blood plasma cholesterol and the increase in blood plasma HDL due to $1.5 \mathrm{~L} / 100 \mathrm{~kg}$ diet of hot water green tea extract, compared to the control, were $4.66 \%$ and $7.14 \%$, respectively. In another study, it was observed that adding green tea extracts to the layers' diets significantly reduced serum cholesterol (130.8 g/dL vs $145.9 \mathrm{~g} / \mathrm{dL})$ and triglycerides (1291.1 g/dL vs $1393.0 \mathrm{~g} / \mathrm{dL}$ ) compared to the control. The ratios of HDL to cholesterol and HDL to LDL were significantly greater in treatment groups than those of the control group (Ariana et al. 2011).
Green tea supplementation of layer diets reduced the cholesterol content of the egg yolk (Biswass \& Wakita 2000). Yamane et al. (1999) demonstrated that the fat content of egg yolks significantly decreased. However, Unganbayar et al. (2005) reported no significant differences in the cholesterol contents of egg yolks between layers that were fed diets containing $0.5 \%, 1.0 \%$ and $1.5 \%$ green tea powder and control diets. They did find that administration of $2.0 \%$ green tea suppressed egg yolk cholesterol significantly compared to that of the positive control treatment. Uuganbayar et al. (2006) reported that the total cholesterol content of egg yolks was slightly reduced in the layers fed $1.0 \%$ or $2.0 \%$ Korean and Japanese green tea diets, but without significant differences. Amongst green tea treatments, Chinese green tea treatments at both $1.0 \%$ and $2.0 \%$ inclusion levels significantly lowered egg yolk cholesterol content compared to that of the control. Ariana et al. (2011) also found that egg yolk cholesterol and triglyceride contents were reduced by green tea supplementation. The caffeine and catechin content of green tea may have an inhibitory effect on intestinal absorption of lipids (Koo \& Sang 2007). Therefore, a green tea diet for birds may prevent an excessive accumulation of lipids in the liver and other tissues, including the egg yolk. The exact mechanism of how green tea by-product decreases yolk cholesterol is as yet unknown. Cholesterol is mainly biosynthesised in the liver of laying hens and integrated into vitellogenin and very low- density lipoprotein particles, which are secreted into the bloodstream and then taken up by growing oocytes through receptor-mediated endocytosis (Elkin 2006). Therefore, it has been suggested that the decrease in the egg yolk cholesterol is dependent on diminution in cholesterol synthesised in the liver. Hence, the decrease in total lipid and cholesterol may be due to the effect of green tea by-products on hepatic 3-hydroxy-3-methylglutaryl coenzyme A reductase that is required for cholesterol synthesis in the liver (Ariana et al. 2011). The conversion of cholesterol to bile acids occurs solely in the liver and represents the main pathway for the removal of cholesterol from the body. This may also explain the reduced in cholesterol levels. Liver weight and liver cholesterol content may also be explained by the disorderly effect of tea catechins on micelle formation. Bile acids can be reabsorbed from the small intestine only in the form of micelles. Green tea catechins prevent the reabsorption of bile acids by disturbing micelle formation and thus increasing bile acid excretion. In order to replenish the loss in bile acids, the conversion of cholesterol to bile acids in the liver will be enhanced and this further decreases the content of liver cholesterol (Myant \& Mitropoulos 1977), which might affect the total cholesterol content of the egg yolk.

\section{Conclusion}

Based on the results of these studies, the addition of green tea by-products to the diets of broilers and layers can improve the productive performance and reduce the cholesterol content in the serum and egg yolk, implying its potential effect on egg-quality parameters. The addition of green tea by-products decreases all microflora counts in the caecum due to an antibiotic-like effect. This information will be 
helpful for poultry nutritionists and the poultry industry. More detailed studies are still needed to elucidate the effect of green tea by-products on poultry nutrition under various circumstances.

\section{Acknowledgement Competing interests}

The author declares that he has no financial or personal relationship(s) which may have inappropriately influenced him in writing this article.

\section{References}

Abdel-Azeem, F.A., 2005, 'Green tea flowers (Camellia sinensis) as natural anti-oxidants feed additives in growing Japanese quail diets', Egyptian Poultry Science Journal 25(3), 569-588.

Abdo, Z.M.A., Hassan, R.A., Amal, A.E. \& Shahinaz, A.H., 2010, 'Effect of adding green tea and its aqueous extract as natural antioxidants to laying hen diet on productive, reproductive performance and egg quality during storage and its content of reproductive performance and egg quality during storage and
cholesterol', Egyptian Poultry Science Journal 30(4), 1121-1149.

Al-Harthi, M.A., 2004, 'Responses of laying hens to different levels of amoxicillin, hot pepper or green tea and their effects on productive performance, egg quality and chemical composition of yolk and blood plasma constituents', Egyptian Poultry Science Journal 24(4), 845-868.

Amidor, T., 2009, 'Wholesome green tea', Food product design, viewed 21 Septembe 2010, from http://www.foodproductdesign.com/articles/2009/07/wholesomegreen-tea.aspx.

Ariana, M., Abdolhossein, S., Mohammad, A.E. \& Rahman, J., 2011, 'Effects of powder and extract form of green tea and marigold, and $\alpha$-tocopheryl acetate on performance, egg quality and egg yolk cholesterol levels of laying hens in lat phase of production', Journal of Medicinal Plants Research 5(13), 2710-2716.

Balentine, D.A., 1997, 'Introduction: Tea and health', Critical Reviews in Food Science and Nutrition 8, 691-669. http://dx.doi.org/10.1080/10408399709527796

Barnes, E.M., Mead, G.C., Barnum, D.A. \& Harry, E.G., 1972, 'The intestinal flora of the chicken in the period 2 to 6 weeks of age, with particular reference to the anaerobic bacteria', British Poultry Science 13, 311-326. http://dx.doi.org/10.1080/

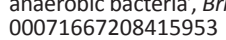

Biswas, M.A.H. \& Wakita, M., 2001a, 'Effect of dietary Japanese green tea powder supplementation on feed utilization and carcass profiles in broilers', Journal of Poultry Science 38, 50-57. http://dx.doi.org/10.2141/jpsa.38.50

Biswas, M.A.H., Miyazaki, Y., Nomura, K. \& Wakita, M., 2000, 'Influences of long-term feeding of Japanese green tea powder on laying performance and egg quality in hens', Asian-Australasian Journal of Animal Sciences 13, 980-985.

Biswas, A.H. \& Wakita, M., 2001b, 'Comparison of two dietary factors, green tea powder feeding and feed restriction, influencing laying performance and egg quality in hens', Bulletin of the Faculty of Bioresources, Mie University 25/26, 55-61.

Bravo, L., 1998, 'Polyphenols: Chemistry, dietary sources, metabolism and nutritional significance', Nutrition Review 56, 317-333. http://dx.doi.org/10.1111/ j.17534887.1998.tb01670.x

Cao, B.H., Karasawa, Y. \& Guo, Y.M., 2005, 'Effects of green tea polyphenols and fructo-oligosaccharides in semi-purified diets on broliers' performance and caecal microflora and their metabolites', Asian-Australasian Journal of Animal Sciences 18, 85-89.

Chaturvedula, V.S.P. \& Prakash, I., 2011, 'The aroma, taste, color and bioactive constituents of tea', Journal of Medicinal Plants Research 5(11), 2110-2124.

Costa, L.M., Gouveia, S.T. \& Nobrega, J.A., 2002, 'Comparison of heating extraction procedures for Al, Ca, Mg and Mn in tea samples', Analytical Sciences 18, 313-318. http://dx.doi.org/10.2116/analsci.18.313

Dalloul, R.A. \& Lillehoj, H.S., 2005, 'Recent advances in immunomodulation and vaccination strategies against coccidiosis', Avian Diseases 49, 1-8. http://dx.doi. org/10.1637/7306-11150R

Deryabin, P.G., Lvov, D.K., Botikov, A.G., Ivanov, V., Kalinovsky, T., Niedzwiecki, A. \& Rath. M., 2008, 'Effects of a nutrient mixture on infectious properties of the highly Rath. M., 2008, 'Effects of a nutrient mixture on infectious properties of the highly
pathogenic strain of avian influenza virus A/H5N1', Biofactors 33, 85-97. http:// pathogenic strain of avian influenza
dx.doi.org/10.1002/biof.5520330201

El-Deek, A.A. \& Al-Harthi, M.A., 2004, 'Responses of modern broiler chicks to stocking density, green tea, commercial multi enzymes and their interactions on productive performance, carcass characteristics, liver composition and plasma constituents', International Journal of Poultry Science 3(10), 635-645. http://dx.doi.org/10.3923/ ijps.2004.635.645

Elkin, R.G., 2006, 'Reducing shell egg cholesterol content. I. Overview, genetic approaches, and nutritional strategies', World's Poultry Science Journal 62, 665-687.

Fujiki, H., 1999, 'Two stages of cancer prevention with green tea', Journal of Cancer Research and Clinical Oncology 125, 589-597. http://dx.doi.org/10.1007/s00 4320050321

Guo, F.C., Williams, B.A., Kwakkel, R.P., Li, H.S., Li, X.P., Luo, J.Y., Li, W.K. \& Verstegen, M.W.A., 2004, 'Effects of mushroom and herb polysaccharides as alternatives fo an antibiotic, on the cecal microbial ecosystem in broiler chickens', Poultry Science 83, 175-182. http://dx.doi.org/10.1093/ps/83.2.175
Guray, E., Ocak, N., Altop, A., Cankaya, S., Aksoy, H.M. \& Ozturk, E., 2011, ‘Growth performance, meat quality and caecal coliform bacteria count of broiler chicks fed diet with green tea extract', Asian-Australasian Journal of Animal Sciences 24(8), diet with green tea extract', Asian-Australasian Journ
1128. http://dx.doi.org/10.5713/ajas.2011.10434

Gadang, VP., Hettiarachchy, N.S., Johnson, M.G. \& Owens, C.M., 2008, 'Evaluation of antibacterial activity of whey protein isolate coating incorporated with nisin, grape seed extract, malic acid, and EDTA on a turkey frankfurter system', Journal of Food Science 73(8), M389-M394. http://dx.doi.org/10.1111/j.1750-3841.2008.00899.x

Hara, H., Orita, N., Hatano, S., Ichikawa, H., Hara, Y., Matsumoto, N., Kimura, Y., Terada, A. \& Mitsuoka, T., 1995, 'Effect of tea polyphenols on fecal flora and fecal metabolic products of pigs', Journal of Veterinary Medical Science 57, 45-49. http:// dx.doi.org/10.1292/jvms.57.45

Hara-Kudo, Y., Yamasaki, A., Sasaki, M., Okubo, T., Minai, Y., Haga, M., Kondo, K. \& Sugita-Konishi, Y., 2005, 'Antibacterial action on pathogenic bacterial spore by green tea catechins', Journal of the Science of Food and Agriculture 85, 2354-2361. http://dx.doi.org/10.1002/jsfa.2259

Hossain, M.E, Seok, Y.K. \& Chul, J.Y., 2012, 'Dietary supplementation of green tea byproducts on growth performance, meat quality, blood parameters and immunity in finishing pigs', Journal of Medicinal Plants Research 6(12), 2458-2467.

Ikigai, H, Nakae, T., Hara, Y. \& Shimamura, T., 1993, 'Bactericidal catechins damage the lipid bilayer', Biochimica et Biophysica Acta 1147, 132-136. http://dx.doi. org/10.1016/0005-2736(93)90323-R

Jang, S.I., Moo-Hyung, J., Hyun, S.L., Rami, A.D., Il-Keun, K., Suk, K. \& Wongi, M., 2007 'Anticoccidial effect of green tea-based diets against Eimeria maxima', Veterinary Parasitology 144, 172-175. http://dx.doi.org/10.1016/j.vetpar.2006.09.005

Kajiya, K., Hojo, H., Suzuki, M., Nanjo, F., Kumazawa, S. \& Nakayama, T., 2004, 'Relationship between antibacterial activity of $(+)$-catechin derivatives and their interaction with a model membrane', Journal of Agricultural and Food Chemistry 52(6), 1514-1519. http://dx.doi.org/10.1021/jf0350111

Kaneko, K., Yamasaki, K., Tagawa, Y., Tokunaga, M., Tobisa, M. \& Furuse, M., 2001, 'Effects of dietary Japanese green tea powder on growth, meat ingredient and lipid accumulation in broil
org/10.2141/jpsa.38.J77

Karori, S.M., Wachira, F.N., Wanyoko, J.K. \& Ngure, R.M., 2007, 'Antioxidant capacity of different types of tea products', African Journal of Biotechnology 6(19), 2287-2296.

Kondo, M., Kazumi, K. \& Hiro-omi, Y., 2007, 'Ensiled or oven-dried green tea by-product as protein feedstuffs: Effects of tannin on nutritive value in goats', Asian-Australasian Journal of Animal Sciences 20(6), 880-886.

Koo, S.I. \& Sang, K.N., 2007, 'Green tea as inhibitor of the intestinal absorption of lipids: Potential mechanism for its lipid-lowering effect', Journal of Nutritional Biochemistry 18(3), 179-183. http://dx.doi.org/10.1016/j.jnutbio.2006.12.005

Labdar, S., 2010, 'Green tea-healthy or unhealthy?', viewed 06 June 2013, from http:// www.articlesbase.com/nutrition-articles/green-tea-healthy-or-unhealthy-3813575. html

Molan, A.L., Meagher, L.P., Spencer, P.A. \& Sivakumaran, S., 2003, 'Effect of flavan-3ols on in vitro egg hatching, larval development and viability of infective larvae of Trichostrongylus colubriformis', International Journal of Parasitology 33, 16911698. http://dx.doi.org/10.1016/S0020-7519(03)00207-8

Molan, A.L., Sivakumaran, S., Spencer, P.A. \& Meagher, L.P., 2004, 'Green tea flavan3-ols and oligomeric proanthocyanidins inhibit the motility of infective larvae of Teladorsagia circumcincta and Trichostrongylus colubriformis in vitro', Research Teladorsagia circumcincta and Trichostrongylus colubriformis in vitro', Research
in Veterinary Science 77, 239-243. http://dx.doi.org/10.1016/j.rvsc.2004.04.010

Murali, N., Kumar-Phillips, G.S., Rath, N.C., Marcy, J. \& Slavik, M.F., 2012, 'Effect of marinating chicken meat with lemon, green tea and turmeric against food borne bacterial pathogens', International Journal of Poultry Science 11(5), 326-332. http:// bacterial pathogens', International Journal
dx.doi.org/10.3923/ijps.2012.326.332

Myant, N.B. \& Mitropoulos, K.A., 1977, 'Cholesterol 7a-hydroxylase', Journal of Lipid Research 18, 135-153.

Naber, E.C., 1979, 'The effect of nutrition on the composition of eggs', Poultry Science 58, 518-528. http://dx.doi.org/10.3382/ps.0580518

Naidu, A.S., 2000, 'Natural food antimicrobial systems', in L.R. Juneja, T. Okubo \& P. Hung (eds.), Catechins, CRC Press, Boca Raton, Florida.

Nishida, T., Eruden, B., Hosoda, K., Nakagawa, K., Miyazawa, T., Shioya, S., 2006 , 'Effects of green tea (Camellia sinensis) waste silage and polyethyleneon ruminal fermentation and blood compone

Perumalla, A.V.S. \& Hettiarachchy, N.S., 2011, 'Green tea and grape seed extracts - potential applications in food safety and quality, review', Food Research International 44(4), 827-839. http://dx.doi.org/10.1016/j.foodres.2011.01.022

Reto, M., Figueira, M.E., Filipe, H.M. \& Almeida, C.M., 2007, 'Chemical composition of green tea (Camellia sinensis) infusions commercialized in Portugal', Plant Foods for Human Nutrition 62(4), 139-144. http://dx.doi.org/10.1007/s11130-007-0054-8

Sadao, K. \& Yuko, Y., 2008, 'Effects of green tea powder feed supplement on performance of hens in the late stage of laying', International Journal of Poultry Science 7(5), 491-496. http://dx.doi.org/10.3923/ijps.2008.491.496

Sahin, K., Orhan, C., Tuzcu, M., Ali, S., Sahin, N. \& Hayirli, A., 2010, 'Epigallocatechin3-gallate prevents lipid peroxidation and enhances antioxidant defense system via modulating hepatic nuclear transcription factors in heat-stressed quails', Poultry Science 89, 2251-2258. http://dx.doi.org/10.3382/ps.2010-00749

Sarker, M.S.K., Kim, G.M. \& Yang, C.J., 2010a, 'Effect of green tea and biotite on performance, meat quality and organ development in Ross broiler', Egyptian Poultry Science Journal 30(1), 77-88.

Sarker, M.S.K., Ko, S.Y., Lee, S.M., Kim, G.M., Choi, J.K. \& Yang, C.J., 2010b, 'Effect of different feed additives on growth performance and blood profiles of Korean Hanwoo calves', Asian-Australasian Journal of Animal Sciences 23, 52-60. 
Shimamura, T., Zhao, W.H. \& Hu, Z., 2007, 'Mechanism of action and potential for use of tea catechin as an anti-infective agent', Anti-Infective Agents in Medicinal use of tea catechin as an anti-infective agent', Anti-Infective Agents in
Chemistry 6, 57-62. http://dx.doi.org/10.2174/187152107779314124

Shomali, T., Najmeh, M. \& Saeed, N., 2012, 'Two weeks of dietary supplementation with green tea powder does not affect performance, D-xylose absorption, and selected serum parameters in broiler chickens', Comparative Clinical Pathology 21(5), 1023-1027. http://dx.doi.org/10.1007/s00580-011-1220-9

Shu, W.S., Zhang, Z.Q., Lan, C.Y. \& Wong, M.H., 2003, 'Fluoride and aluminum concentrations of tea plants and tea products from Sichuan Province, PR China', Chemosphere 52, 1475-1482. http://dx.doi.org/10.1016/S0045-6535(03)00485-5

Song, J.M., Park, K.D., Lee, K.H., Byun, Y.H., Park, J.H., Kim, S.H., Kim, J.H. \& Seong, B.L., 2007, 'Biological evaluation of anti-influenza viral activity of semi-synthetic catechin derivatives', Antiviral Research 76, 178-185. http://dx.doi.org/10.1016/j. antiviral.2007.07.001

Taylor, P.W., Hamilton-Miller, J.M.T. \& Stapleton, P.D., 2005, 'Antimicrobial properties of green tea catechins', Food Science Technology Bulletin 2, 71-81.

Terada, A., Hara, H., Nakajyo, S., Ichikawa, H., Hara, Y., Fukai, K., Kobayashi, Y. \& Mitsuoka, T., 1993, 'Effect of supplements of tea polyphenols on the caecal flora and caecal metabolites of chicks', Microbial Ecology in Health and Disease 6, 3-9. $\mathrm{http}: / / \mathrm{dx}$.doi.org/10.3109/08910609309141555

Toghyani, M., Toghyani, M., Gheisari, A., Chalamkari, G. \& Mohammadrezaei, M., 2010, 'Growth performance, serum biochemistry and blood hematology of broiler chicks fed different levels of black seed (Nigella sativa) and peppermint (Menthapiperita)', Livestock Science 129, 173-178, viewed 06 June 2013, from http://www. sciencedirect.com/science/article/pii/S1871141310000387

Uuganbayar, D., 2004, 'A study on the utilization of green tea for laying hens and broiler chicks', Dissertation for the degree of Doctor of Philosophy Sunchon National University, Suncheon, Korea.

Uuganbayar, D., Bae, I.H., Choi, K.S., Shin, I.S., Firman, J.D. \& Yang, C.J., 2005, 'Effects of green tea powder on laying performance and egg quality in laying hens', AsianAustralasian Journal of Animal Science 18(12), 1769-1774.
Uuganbayar, D., Shin, I.S. \& Yang, C.J., 2006, 'Comparative performance of hens fed diets containing Korean, Japanese and Chinese green tea', Asian-Australasian Journal of Animal Sciences 19(8), 1190-1196.

Wang, H., Provan, G.J., Helliwell, K., 2000, 'Tea flavonoids: Their functions, utilization, and analysis', Trends in Food Science and Technology 11, 152-160. http://dx.doi. org/10.1016/S0924-2244(00)00061-3

Wheeler, D.S. \& Wheeler, W.J., 2004, 'The medicinal chemistry of tea', Drug Development Research, 61(2), 45-65. http://dx.doi.org/10.1002/ddr.10341

Windisch, W., Schedle, K., Plitzner, C. \& Kroismayr, A., 2007, 'Use of phytogenic products as feed additives for swine and poultry', Journal of Animal Science 86(14), suppl. E140-E148, viewed 06 June 2013, from (http://www.journalofanimalscience.org/ content/86/14_suppl/E140.full.pdf+html.

Xu, J., Zhu, S.G., Yang, F.M., Cheg, L.C., Hu, Y., Pan, G.X. \& Hu, Q.H., 2003, 'The influence of selenium on the antioxidant activity of green tea', Journal of the Science of Food and Agriculture 83, 451-455. http://dx.doi.org/10.1002/jsfa.1405

Yamane, T., Goto, H., Takahashi, D., Takeda, H., Otowaki, K. \& Tsuchida, T., 1999, 'Effects of hot water extracts of tea on performance of laying hens', Japan Poultry Science 36, 31-37. http://dx.doi.org/10.2141/jpsa.36.31

Yang, C.J., Yang, I.Y., Oh, D.H., Bae, I.H., Cho, S.G., Kong, I.G., Uuganbayar, D., Nou, I.S. \& Choi, K.S., 2003, 'Effect of green tea by-product on performance and body composition in broiler chicks', Asian-Australasian Journal of Animal Sciences 16 867-872.

Yilmaz, Y., 2006, 'Novel uses of catechins in foods', Trends in Food Science and Technology 17, 64-71. http://dx.doi.org/10.1016/j.tifs.2005.10.005

Yoda, Y., Hu, Z.Q., Zhao, W.H. \& Shimamura, T., 2004, 'Different susceptibilities of Staphylococcus and Gram-negative rods to epigallocatechin gallate', Journal of Infection and Chemotherapy 10, 55-58. http://dx.doi.org/10.1007/s10156-0030284-0

Yun, C.H., Lillehoj, H.S., Zhu, J., Min, W., 2000, 'Kinetic differences in intestinal and systemic interferon-gamma and antigen-specific antibodies in chickens experimentally systemic interferon-gamma and antigen-specific antibodies in chickens experimentally
infected with Eimeria maxima', Avian Diseases 44, 305-312. http://dx.doi.org/ $10.2307 / 1592544$ 